\title{
Digested formula but not digested fresh human milk causes death of intestinal cells in vitro: implications for necrotizing enterocolitis
}

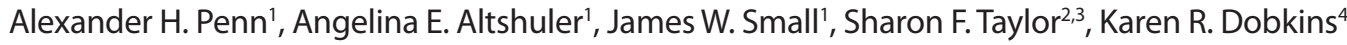 \\ and Geert W. Schmid-Schönbein ${ }^{1}$
}

BACKGROUND: Premature infants fed formula are more likely to develop necrotizing enterocolitis (NEC) than those who are breastfed, but the mechanisms of intestinal necrosis in NEC and protection by breast milk are unknown. We hypothesized that after lipase digestion, formula, but not fresh breast milk, contains levels of unbound free fatty acids (FFAs) that are cytotoxic to intestinal cells.

METHODS: We digested multiple term and preterm infant formulas or human milk with pancreatic lipase, proteases (trypsin and chymotrypsin), lipase + proteases, or luminal fluid from a rat small intestine and tested FFA levels and cytotoxicity in vitro on intestinal epithelial cells, endothelial cells, and neutrophils.

RESULTS: Lipase digestion of formula, but not milk, caused significant death of neutrophils (ranging from 47 to $99 \%$ with formulas vs. $6 \%$ with milk) with similar results in endothelial and epithelial cells. FFAs were significantly elevated in digested formula vs. milk and death from formula was significantly decreased with lipase inhibitor pretreatment, or treatments to bind FFAs. Protease digestion significantly increased FFA binding capacity of formula and milk but only enough to decrease cytotoxicity from milk.

CONCLUSION: FFA-induced cytotoxicity may contribute to the pathogenesis of NEC.

N ecrotizing enterocolitis (NEC) is currently the leading cause of death from gastrointestinal disease in premature infants (1). It is characterized by abdominal distension, hemorrhage and necrosis of tissue within the intestine, peritonitis following intestinal perforation, and a rapid progression from initial discomfort to death (1).

Its cause is unknown, but NEC is rarely seen before oral feedings are initiated (2). Formula-fed premature infants have a greater risk of developing NEC than those fed with breast milk only (3), but the mechanism whereby breast milk protects from NEC is not completely understood (4). Current theories suggest that gut bacterial colonization and inflammation may play a role, but these theories do not include a mechanism for the intestinal necrosis.
A mechanism that has received little to no attention in the pathophysiology of NEC is direct cytotoxicity of luminal content on intestinal tissue. We have observed that homogenates of digested food collected from the intestinal lumen of healthy rats, but not those of undigested food, are cytotoxic (5). This cytotoxicity results in intestinal hemorrhagic necrosis under ischemic conditions (6) that is similar to the intestinal hemorrhagic necrosis seen in NEC in infants. The cytotoxicity is likely due to the creation and transport of unbound, nonesterified (i.e., "free") fatty acids (FFAs), formed during the digestion process, into the intestinal wall (6). A study in 1990 found antibacterial and antiviral activity, attributed to FFAs, in gastric aspirates of formulafed infants (7), suggesting that digested formula could also damage intestinal tissue under ischemic or similar conditions.

Intestinal ischemia is known to cause a failure of the intestinal mucosal barrier, resulting in increased intestinal permeability (8). This allows transport of bacteria (9) and other molecules from the intestinal lumen into the intestinal wall (10). Eventually, multiple organ failure and death from shock can result. Increased intestinal permeability also occurs in premature infants (11) and remains high for extended periods in those premature infants who are fed infant formula as opposed to breast milk (12). Increased intestinal permeability may represent a common causal factor for hemorrhagic necrosis in NEC and intestinal ischemia.

Given that breast milk lowers the risk of NEC, if intestinal damage in NEC is caused to some degree by entry of cytotoxic FFAs into the intestinal wall, then there should be a measurable difference in the cytotoxicity of digested fresh breast milk as compared with digested formula. Therefore, we tested the cytotoxicity of breast milk and several term and preterm infant formulas after digestion by selected pancreatic-derived digestive enzymes.

Our results indicate that numerous digested formulas are cytotoxic, whereas digested fresh breast milk is not. We show that cytotoxicity is due to the detergent action of high concentrations of FFAs, a mechanism for cell death that is independent of cell type.

'Department of Bioengineering, University of California, San Diego, La Jolla, California; '2Department of Pediatrics, University of California, San Diego, La Jolla, California; ${ }^{3}$ Department of Pediatrics, Rady Children's Hospital, San Diego, San Diego, California; ${ }^{4}$ Department of Psychology, University of California, San Diego, La Jolla, California. Correspondence: Alexander H. Penn (apenn@bioeng.ucsd.edu) 


\section{RESULTS}

\section{Cytotoxicity of Digested Formula vs. Fresh Breast Milk}

Our first objective was to determine if digestion would cause either formula or breast milk to become cytotoxic. Although there was some variability, all nine formulas digested with lipase (with or without protease) and skimmed (i.e., the supernatant under the solid fat layer after centrifugation) were highly cytotoxic, as measured by human neutrophil death after $1 \mathrm{~h}$ (Table 1). In contrast, identically treated fresh human milk was not cytotoxic. Enzymeonly controls: lipase alone or lipase and proteases together, on neutrophils for $1 \mathrm{~h}$ caused no appreciable cell death $(9.1 \pm 6.5$ and $9.8 \pm 6.3 \%$ death, respectively, vs. $10.0 \pm 6.9 \%$ death after $1 \mathrm{~h}$ of phosphate-buffered saline (PBS) alone). Similar to neutrophils exposed to other biologic solutions with high concentrations of FFAs $(5,6)$, neutrophils exposed to digested formula and milk show dramatic perturbations of the cell membranes (i.e., large blebs) (Figure 1). Although blebs were rare in the milk group, nearly every cell in the formula group had evidence of a ruptured bleb. We have seen previously that rupturing of a bleb reduces the apparent size of the cell back down to approximately control levels as measured by forward scatter in flow cytometry, and coincides with the entry of the loss-of-viability indicator, propidium iodide (PI), into the cell (i.e., cell death) through the opening in the plasma membrane (5).

We then determined whether these phenomena were dependent on cell type or species and whether the pattern of response would remain the same if samples were not skimmed. Shortterm $(5 \mathrm{~min})$ incubation of lipase-digested whole formula, but not lipase-digested whole human milk, with bovine aortic endothelial cells and intestinal epithelial cells (IECs) also led to high levels of cytotoxicity (Table 2), despite a 10-fold lower concentration of applied digestive enzymes $(0.1 \mathrm{mg} / \mathrm{ml})$. The short incubation time also supports a necrotic, rather than apoptotic, mechanism. Of note, even control (PBS-digested) formula caused more cell death than breast milk in all three cell types, although this increase was significant for only two of the formulas (Table 1).
To better match the digestive enzyme profile present in the intestine, we tested whether formula or breast milk digested with endogenous enzymes from the lumen of the rat intestine would be cytotoxic to rat IECs. We again found that formula, but not breast milk, digested with luminal fluid was cytotoxic (Table 2).

When examining the effects of protease digestion on formula and breast milk, we observed that addition of the proteases trypsin and chymotrypsin to breast milk significantly reduced the already small amount of cell death in the control (Table 1). Many of the formulas also demonstrated a lower cytotoxicity than basal (control) levels if digested by protease. If combined with lipase digestion, protease digestion also significantly decreased the cytotoxicity of some formulas (Table 1), although it significantly increased the cytotoxicity of Enfamil Infant formula (Mead Johnson \& Company, Glenview, IL) $(P<0.0005)$. Formula digested with proteases but without lipase remained noncytotoxic.

\section{FFA Cytotoxic Mechanism}

Lipase-digested formula cytotoxicity was prevented only if a lipase inhibitor, orlistat, was added at the beginning of the digestion period rather than at the end of digestion, confirming that lipase activity during digestion is the key requirement for cell death to occur (Figure 2a). Filtering cytotoxic digested formula with glass fiber filters, which bind and remove FFAs (Figure 3), significantly reduced cytotoxicity (Figure $2 \mathrm{~b}$ ). Likewise, addition of fatty acid-free bovine serum albumin, a protein capable of binding FFAs, immediately before adding to cells significantly reduced cell death from digested formula (Figure $2 \mathbf{b}$ ), suggesting that cell death is a consequence of the presence of unbound FFAs.

To confirm differences in the concentration of FFAs in cytotoxic vs. noncytotoxic samples, we measured total, bound, and by subtraction, unbound FFA concentrations in aliquots of the same skimmed solutions tested for cytotoxicity on human neutrophils (Table 1), stored at $-80^{\circ} \mathrm{C}$ until testing (Figure 4). We

Table 1. Neutrophil cell death after $1 \mathrm{~h}$ exposure

\begin{tabular}{|c|c|c|c|c|}
\hline & With PBS & With protease & With lipase & With lipase + protease \\
\hline Fresh human milk & $3.0 \pm 1.7$ & $1.5 \pm 1.2^{\mathrm{a}}$ & $6.2 \pm 7.4$ & $7.4 \pm 12.3$ \\
\hline Enfamil Infant & $10.1 \pm 7.3$ & $5.5 \pm 8.6^{\mathrm{a}}$ & $60.0 \pm 15.6^{\mathrm{b}, \mathrm{c}}$ & $85.9 \pm 11.6^{\mathrm{b}, \mathrm{c}}$ \\
\hline Similac Advance & $8.6 \pm 7.3$ & $5.8 \pm 7.4$ & $93.4 \pm 3.3^{\mathrm{b}, \mathrm{c}}$ & $94.3 \pm 4.0^{\mathrm{b}, \mathrm{c}}$ \\
\hline Similac Soy & $4.3 \pm 2.1$ & $4.1 \pm 2.0$ & $70.8 \pm 13.5^{\mathrm{b}, \mathrm{c}}$ & $77.8 \pm 13.0^{\mathrm{b}, \mathrm{c}}$ \\
\hline Enfamil Premature $20 \mathrm{kcal} / \mathrm{oz}$ & $9.8 \pm 4.9$ & $2.9 \pm 1.1^{\mathrm{a}}$ & $95.0 \pm 3.1^{\mathrm{b}, \mathrm{c}}$ & $25.0 \pm 7.9^{\mathrm{a}, \mathrm{a}, \mathrm{c}}$ \\
\hline Enfamil EnfaCare $22 \mathrm{kcal} / \mathrm{oz}$ & $11.6 \pm 2.6^{c}$ & $3.7 \pm 1.2^{\mathrm{a}}$ & $46.7 \pm 10.1^{\mathrm{b}, \mathrm{c}}$ & $43.7 \pm 9.1^{b, c}$ \\
\hline Similac Special Care $20 \mathrm{kcal} / \mathrm{oz}$ & $12.6 \pm 3.1$ & $5.3 \pm 1.7^{\mathrm{a}}$ & $97.0 \pm 0.4^{b, c}$ & $67.0 \pm 11.8^{\mathrm{a}, \mathrm{b}, \mathrm{c}}$ \\
\hline Similac Expert Care NeoSure $22 \mathrm{kcal} / \mathrm{oz}$ & $16.5 \pm 5.6$ & $4.9 \pm 0.9^{\mathrm{a}}$ & $90.7 \pm 1.9^{b, c}$ & $65.1 \pm 8.8^{\mathrm{a}, \mathrm{b}, \mathrm{c}}$ \\
\hline Similac Special Care 24 kcal/oz & $13.2 \pm 2.9^{c}$ & $9.3 \pm 1.4$ & $98.9 \pm 0.3^{b, c}$ & $96.7 \pm 0.9^{b, c}$ \\
\hline
\end{tabular}

Percentage of mean \pm SD. Samples defatted after digestion $\left(2 \mathrm{~h}, 37^{\circ} \mathrm{C}\right)$. Enzyme concentrations: $1 \mathrm{mg} / \mathrm{ml} . \mathrm{N}=12 \mathrm{breast}$ milk donors, $n=11,5,5,5,4,4,4,4,4$, and 4 independent replicates with formulas (in order listed). The interaction in the two-factor mixed ANOVA (milk vs. each formula—between subjects; digestion category—-within subjects) was significant $\left(P<0.05 ; \eta_{p}^{2}=0.92\right)$.

PBS, phosphate buffered saline.

aLess cell death vs. without protease $(P<0.02)$. $P<0.025$ considered significant. ${ }^{b}$ More cell death vs. without lipase $(P<0.007)$. $P<0.025$ considered significant. ${ }^{C}$ More cell death vs. breast milk $(P<0.005$ ); note in PBS column all formulas except Similac Advance and Similac Soy had $P<0.02$ (but $P<0.005$ was cutoff for significance by Bonferroni test due to number of comparisons) 


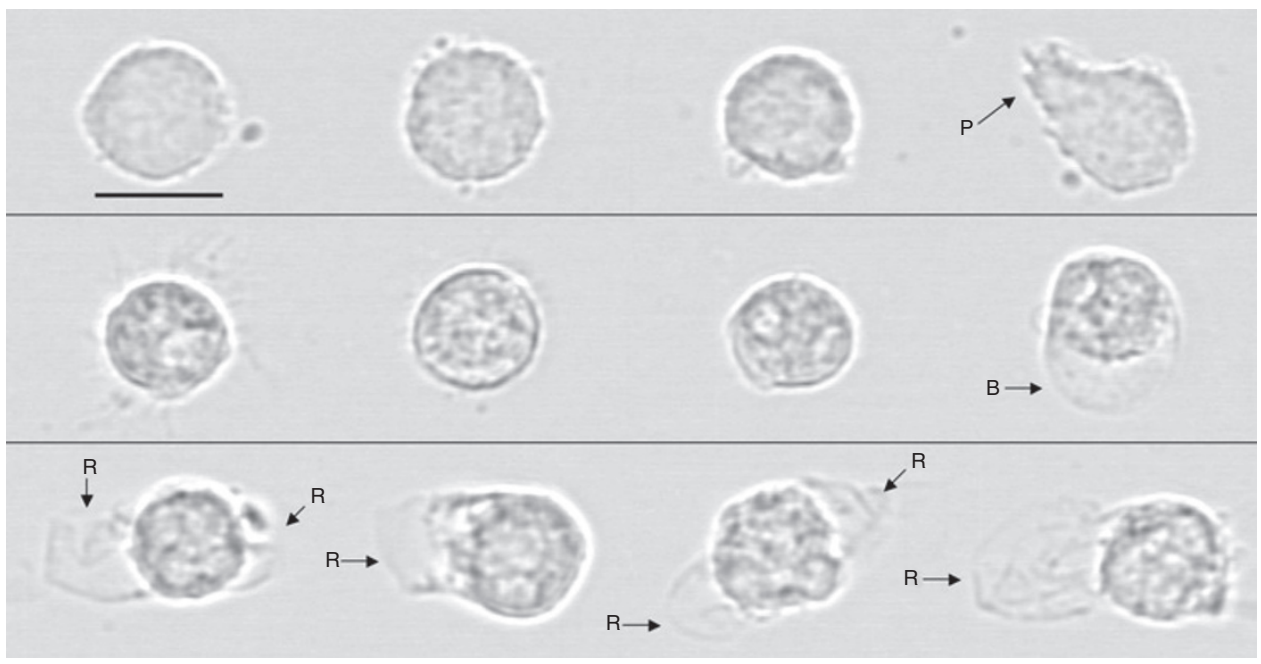

Figure 1. Representative images of human neutrophils exposed for $60 \mathrm{~min}$, before glutaraldehyde fixation, to (top row) lipase (as control), (middle row) human milk (from $-80^{\circ} \mathrm{C}$ storage) digested with lipase, or (bottom row) infant formula (Enfamil Infant) digested with lipase. Cells exposed to high levels of free fatty acids form blebs-hemispherical balloon-like projections of the cell membrane away from the underlying cytoskeleton-pressurized by the slight osmotic gradient between a cell and its surroundings (present even in solutions of physiologic osmolarity). Eventually these blebs rupture, killing the cells, and allowing entry of the life/death indicator, propidium iodide. Of the 12 cells we observed under the microscope in the milk + lipase group, only one showed a bleb (included here to show the appearance of a bleb before rupture). All blebs from the formula + lipase group had already ruptured, as shown by loss of bleb spherical shape. B, bleb; P, pseudopod; R, ruptured bleb. Bar $=10 \mu \mathrm{m}$ (800x original magnification).

Table 2. Bovine aortic endothelial cell (BAEC) and rat intestinal epithelial cell (IEC) death after 5 min exposure

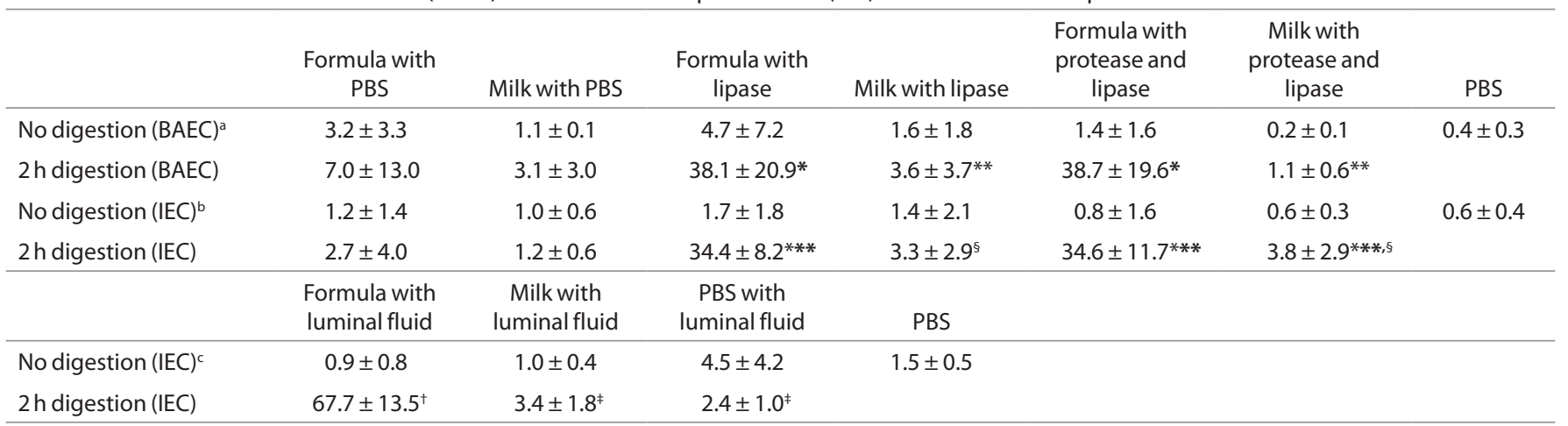

Percentage of mean \pm SD. No defatting after digestion ( 0 or $2 \mathrm{~h}, 37^{\circ} \mathrm{C}$ ). Purified enzyme concentrations: $0.1 \mathrm{mg} / \mathrm{ml}$. Cell death normalized by average number of propidium iodidepositive cells $/ \mathrm{mm}^{2}$ with Triton X-100 (1,085 $\pm 104,809 \pm 123$, and $510 \pm 52$ cells/mm² for BAECs, IEC (purified enzymes), and IEC (luminal fluid), respectively). $P<0.017$ considered significant for all comparisons.

PBS, phosphate buffered saline.

an for BAEC study $=16$ wells for formula groups, three donors of fresh breast milk. Performed three-factor mixed ANOVA (substrate —-between subjects, digestion category — within subjects, and digestion time-within subjects). The three-way interaction was significant $\left(P<0.05 ; \eta_{p}{ }^{2}=0.24\right) .{ }^{b} n$ for IEC study using purified enzymes $=11$ wells for formula groups, 12 donors of breast milk (stored $-80^{\circ} \mathrm{C}$ ). Performed three-factor mixed ANOVA (substrate—between subjects, digestion category —-within subjects, and digestion time — within subjects). The three-way interaction was significant $\left(P<0.05 ; \eta^{2}=0.75\right)$. ${ }^{2} n$ for IEC study using luminal fluid $=$ five wells for formula or PBS with luminal fluid, five donors of breast milk (stored $-80^{\circ} \mathrm{C}$ ). The interaction in the two-factor mixed ANOVA (substrate-between subjects, and digestion time-within subjects) was significant $\left(P<0.05 ; \eta_{p}{ }^{2}=0.94\right)$. ${ }^{*} P<2 \times$ $10^{-6}$ vs. no digestion; ${ }^{* *} P<8 \times 10^{-5}$ vs. equivalent formula group; ${ }^{* * *} P<0.002$ vs. no digestion; ${ }^{\S} P<6 \times 10^{-6}$ vs. equivalent formula group; ${ }^{\dagger} P<5 \times 10^{-4}$ vs. no digestion; ${ }^{\ddagger} P<4 \times 10^{-4}$ vs. formula group.

detected little to no FFAs in fresh milk or formula incubated with PBS or proteases. Lipase digestion increased the total FFAs in both fresh breast milk and formula, but to significantly higher levels in formula. Moreover, the amounts of FFAs that were unbound in fresh milk digested with lipase or with lipase and protease were significantly less than in the lipase or lipase and protease-digested formula. Of note, protease digestion decreased the total FFA levels in all cases (except for formula with PBS, which had no FFAs to reduce). Overall, unbound FFA concentration correlated with neutrophil cytotoxicity (correlation coefficient $=0.766$ ).
Pilot studies using samples that were not skimmed suggest that the FFA concentrations in the lipase-digested formula may be more than an order of magnitude higher than in the skimmed samples in Figure 4. However, the degree of dilution required to make samples (containing fat globules) readable by a plate reader greatly reduced the precision of the measurements, and thus this aspect was not studied here.

\section{Protection by Proteases}

We hypothesized that protease digestion of breast milk and formula may provide its protection from FFA-induced necrosis 


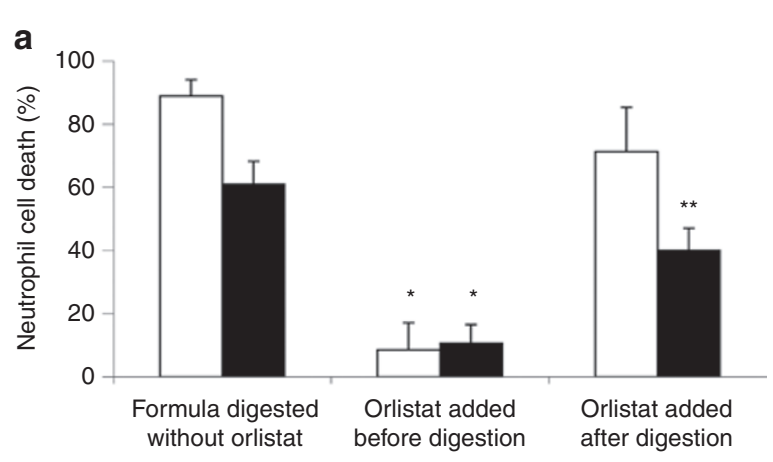

b

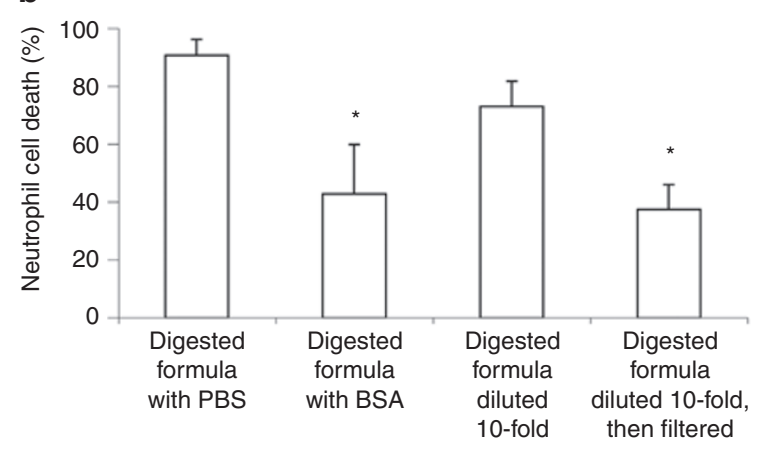

Figure 2. Cell death (neutrophil) with and without interventions against free fatty acid (FFA)-derived cytotoxicity from digested, then skimmed, formula. (a) Death caused by digestion of formula with protease + lipase (white bars) or luminal fluid (black bars) without or with $0.25 \mathrm{mg} / \mathrm{ml}$ orlistat added at the beginning or the end of digestion. Formula, lipase, or luminal fluid alone did not cause cell death (not shown). Single-factor ANOVAs (separate for each digestion type) were significant (both $P<$ $0.05 ; \eta_{p}^{2}=0.97$ for protease + lipase digestion; $\eta_{p}^{2}=0.96$ for luminal fluid digestion); $P<0.017$ considered significant for pair-wise comparisons. ${ }^{*} P$ $<0.0023$ less death vs. without orlistat; ${ }^{* *}$ more death $(P<0.013)$ than if orlistat is added before digestion but less death $(P<0.0005)$ than without orlistat (reflecting the extra digestion that the group without orlistat gets during the $1 \mathrm{~h}$ incubation with cells). $n=4$. (b) Death caused by protease and lipase digested formula mixed 9:1 with either phosphate buffered saline or $200 \mathrm{mg} / \mathrm{ml}$ fatty acid-free bovine serum albumin (BSA) to bind unbound FFAs, or with and without filtering through five glass fiber filters (after tenfold dilution to bring fatty acid concentration down to a level where this degree of filtering could be effective). $P<0.05$ considered significant. *Significantly $\left(P<8 \times 10^{-5}\right)$ reduced cell death with BSA addition or filtering $(n=8)$.

by increasing the overall number of protein/fatty acid binding sites (e.g., by exposing hydrophobic cores of globular proteins). Accordingly, we compared the ability of whole human milk (stored at $-80^{\circ} \mathrm{C}$ ), protease-digested whole human milk, whole formula (Enfamil Infant), and protease-digested whole formula to protect IECs from otherwise cytotoxic concentrations of the FFA, oleic acid, added exogenously at the end of digestion and immediately before addition to cells (Figure 5). We observed a significant difference in the level of protection between milk and formula with $35 \mathrm{mmol} / \mathrm{l}$ oleic acid. However, prior protease digestion of either milk or formula significantly reduced the amount of cell death caused by exogenous oleic acid. This suggests that the FFA binding capacity of both fluids increased with addition of protease, although our other results suggest this was only sufficient to decrease cytotoxicity from breast milk, not lipase-digested Enfamil Infant formula

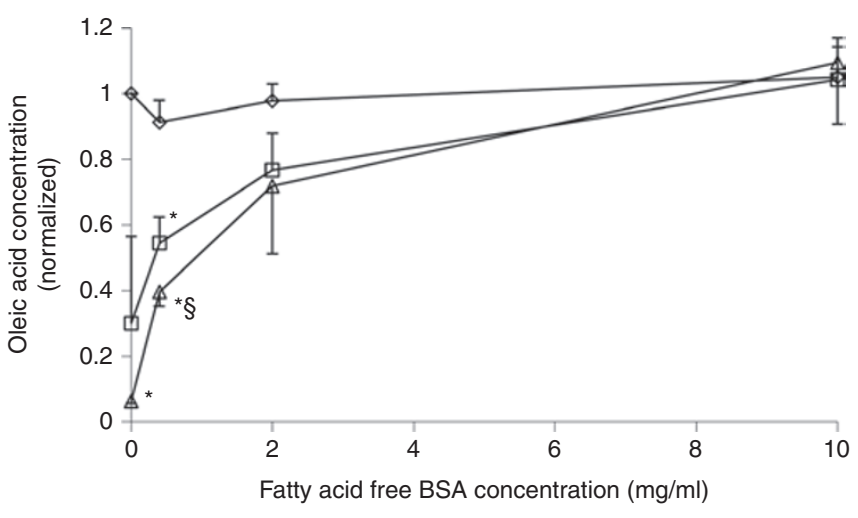

Figure 3. Oleic acid preparations $(\sim 0.5 \mathrm{mmol} / \mathrm{l}, 0.9 \%$ ethanol, $10 \mathrm{mmol} / \mathrm{l}$ phosphate buffered saline final) in $0-10 \mathrm{mg} / \mathrm{ml}$ bovine serum albumin (BSA) (binds free fatty acids (FFAs)), before filtration (diamonds) or after three (squares) or five (triangles) serial filtrations of $900 \mu \mathrm{l}$ through glass fiber filters ( $n=3$, normalized to the oleic acid concentration without BSA before filtering). FFA quantification is unaffected by the presence of BSA before filtration. After five serial filtrations, in the presence of $10 \mathrm{mg} / \mathrm{ml}$ BSA, the FFA concentration was unchanged. In the absence of the fatty acid binding protein the glass fiber filtration removed essentially all of the FFAs. The interaction in the two-factor (filtration and BSA concentration) ANOVAs was significant $\left(P<0.05, \eta_{\mathrm{p}}^{2}=0.81\right) ; P<0.01$ considered significant for pair-wise comparisons. *Less oleic acid vs. before filtration $(P<0.004)$. §More oleic acid vs. without BSA $(P<0.01$; five-filtered 2 and $10 \mathrm{mg} / \mathrm{ml}$ solutions approached significance, $P=0.033$ and $P=0.011$, respectively).

(although other formulas may receive more benefit from protease digestion).

\section{DISCUSSION}

Cell death after exposure to digested formula was rapid, under $5 \mathrm{~min}$ in some cases, and involved a physical destruction of cell membranes as indicated by large bleb formations and ruptures. Cell death occurred regardless of cell type and species of origin and depended on the formation and presence of unbound FFAs. Collectively this evidence suggests that the cell death is from the detergent action of FFAs directly on the cell membranes. Therefore, this is a different type of damage mechanism than those considered in the intestine that depend on pathogens or specific cell-surface proteins.

Although cell death through this mechanism is not dependent on bacteria, bacteria may further increase the concentration of FFAs, especially in the colon, as undigested carbohydrates that reach the colon are metabolized by bacteria into short-chain FFAs (13). These short-chain fatty acids are released into the intestinal lumen and, in low concentrations, they serve as food for the intestine and help reduce intestinal permeability (13). However in high concentrations, short-chain fatty acids could increase the cytotoxicity of luminal fluid even further and have been shown in a quail model to cause NEC-like morphological changes in the colon $(13,14)$.

In this study, neutrophils were chosen as one of our cell types for practical reasons. However, in addition to the lysosomal catabolic enzymes and other inflammatory mediators that would be released from nearly every human cell type undergoing necrosis, necrosis of neutrophils would result in 


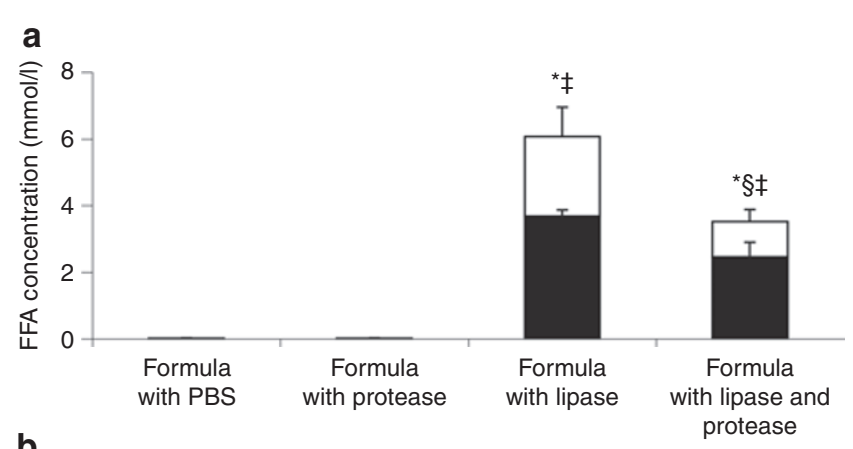

b

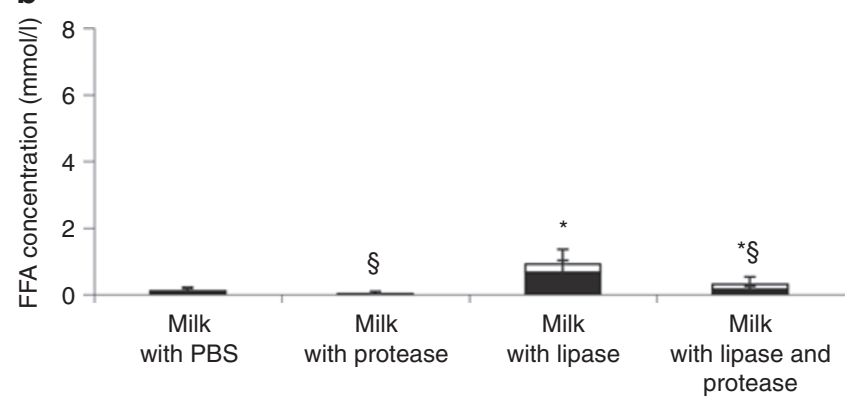

Figure 4. Total (full columns) and bound (black portions of columns) free fatty acid (FFA) concentrations in (a) formula or (b) milk after digestion and subsequent skimming (i.e., aliquots of the same solutions tested for cytotoxicity in Figure 1 , frozen at $-80^{\circ} \mathrm{C}$ until FFA concentration analysis). The differences between the total and bound FFAs (white portion of columns) represent the concentrations of unbound FFAs. Significances shown in the figure refer only to total FFA levels. The interactions in the two-factor mixed ANOVAs (food source-between subjects; digestion type-within subjects) for total and unbound FFA concentrations were significant (both $P<0.05, \eta_{p}^{2}=0.95$ for total FFAs, $\eta_{p}^{2}=0.79$ for unbound FFAs); $P<0.017$ considered significant for pair-wise comparisons. ${ }^{*} P<6 \times 10^{-4}$ in total FFA with vs. without lipase digestion. $¥ P<3 \times 10^{-4}$ in total FFA in formula group vs. equivalent milk group. §Significant $(P<0.009)$ decrease in total FFA with protease digestion. $n=12$ for milk and 5 for formula. Significant differences in unbound FFAs were identical to those of total FFAs, with the following exceptions: unbound FFAs in milk digested with lipase and protease were not quite significantly higher than if digested with protease alone $(P=0.019)$ and unbound FFAs were not significantly reduced with protease digestion ( $P=0.035$ for formula with lipase and protease vs. with lipase only).

uncontrolled release of their many bactericidal mediators. If this occurs in the intestine, it could enhance the damage to intestinal tissue.

Formula is designed to have approximately the same overall fat content as breast milk, yet every digested formula we tested was more cytotoxic than breast milk and cytotoxicity appears due to increased FFA levels. One possible explanation could be that breast milk deactivates pancreatic lipase and/or formula activates it. Another possibility is that the composition of fats, or form of lipid vesicular packaging, in breast milk may be less susceptible to lipase digestion. For example, fat globule diameter is at least sixfold greater in milk than formula (15). As this would greatly decrease the overall surface:volume ratio of the fat, the reaction kinetics, and thus the rate of FFA generation in milk, may be greatly reduced (16). FFAs may also be elevated in the intestines of formula-fed infants due to poor absorption of long-chain saturated FFAs (17). For example, whereas in human milk the long-chain fatty acid palmitic acid is primarily

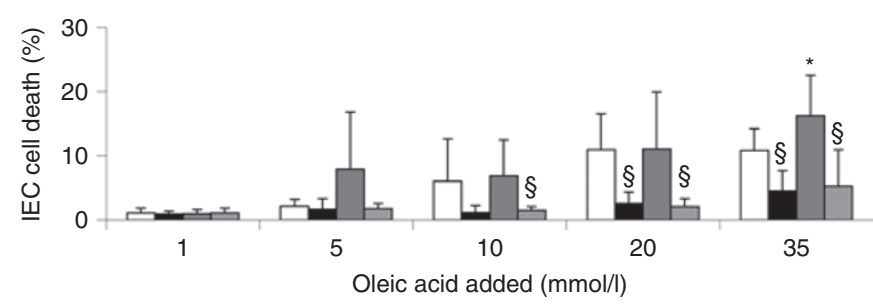

Figure 5. Intestinal epithelial cell death caused by whole milk or formula (stored at $-80^{\circ} \mathrm{C}$ ) digested for $2 \mathrm{~h}$ at $37^{\circ} \mathrm{C}(4: 1)$ with phosphate buffered saline or $0.5 \mathrm{mg} / \mathrm{ml}$ trypsin and chymotrypsin (each $0.1 \mathrm{mg} / \mathrm{ml}$ final concentration) (milk: white bar, formula: gray bar, milk + protease: black bar, formula + protease: hatched bar) and after addition of exogenous oleic acid in varying concentrations. The results reveal the concentrations of exogenous oleic acid at which cytotoxicity arises, i.e., the points at which free fatty acid binding capacity is exhausted. The two-factor mixed ANOVAs (food source-between subjects; digestion type-within subjects) yielded a significant main effect of digestion type at the $5,10,20$, and $35 \mathrm{mmol} / \mathrm{l}$ oleic acid concentrations $\left(P<0.05, \eta_{p}{ }^{2}=0.52\right.$ for $5 \mathrm{mmol} / \mathrm{l}, \eta_{\mathrm{p}}{ }^{2}=0.40$ for $10 \mathrm{mmol} / \mathrm{l}, \eta_{p}^{2}=0.70$ for $20 \mathrm{mmol} / \mathrm{l}, \eta_{p}^{2}=0.76$ for $\left.35 \mathrm{mmol} / \mathrm{l}\right)$. There was also a significant interaction at $5 \mathrm{mmol} / \mathrm{l}\left(P<0.05, \eta_{p}{ }^{2}=0.48\right) ; P<0.025$ considered significant for pair-wise comparisons. ${ }^{*} P<0.025$ vs. milk; $\S P<0.008$ vs. without protease. $n=12$ wells for the formula group, six wells for the formula + protease group, and nine donors of breast milk. Milk with vs. without protease at $10 \mathrm{mmol} / \mathrm{l}$ oleic acid approached significance $(P=0.06)$ as did milk vs. formula and formula vs. formula + protease at $5 \mathrm{mmol} / \mathrm{l}$ oleic acid $(P=0.05$ and $P=0.04$, respectively).

at the sn-2 position and is readily absorbed as a monoglyceride by intestinal cells, palmitic acid is primarily located at the sn-1, 3 positions of triglycerides in most formulas and is thus deesterified by pancreatic lipase, which preferentially cleaves at those positions (17). Poorly absorbed free palmitic acid could then accumulate in the intestinal lumen.

Our findings differ from those in the study with gastric aspirates (7), which reported comparable antibacterial and antiviral (i.e., cytotoxic) activity between aspirates of formula-fed infants and breast milk-fed infants. The disparity from the current results may be because food was sampled before it could be exposed to pancreatic enzymes, which as shown here can have a differential effect on breast milk vs. formula.

We expect that, like formula and unlike breast milk, most food containing fat releases high concentrations of FFAs upon lipase digestion. Since unbound FFAs may be cytotoxic at concentrations as low as $1 \mu \mathrm{mol} / \mathrm{l}$ (6), typical digested food is likely to be cytotoxic. An intact intestinal mucosal barrier must therefore provide protection for older children and adults from high concentrations of FFAs in digested food, although the exact mechanism of protection remains to be determined.

There are conditions, however, in which the mucosal barrier fails or is not yet fully present, such as during the intestinal ischemia before shock mentioned above. Likewise, the intestine is in an immature, permeable state at birth (18); it is even more permeable in preterm infants (11). Both the neonatal intestine and breast milk appear to be optimized to reduce exposure of a permeable intestine to cytotoxic molecules. As we saw here, pancreatic lipase-digested breast milk has fewer FFAs and is less cytotoxic than lipase-digested formula. Digestion with pancreatic proteases reduces breast milk cytotoxicity even further, possibly by exposing new FFA binding sites within milk proteins. 
Breast milk also contains the neuropeptide somatostatin (19), which reduces the secretion of digestive enzymes into the lumen of the intestine (20). Before weaning, infants produce little to no pancreatic lipase, instead relying on pancreatic lipase-related protein 2 and bile-salt sensitive lipase from the pancreas and milk (21), which, while having a broader specificity (able to cleave all three fatty acid positions in triglycerides and phospholipids as well), are actually less efficient at lipid digestion in milk than pancreatic lipase (16). In animal models, early weaning triggers full maturation of the intestine into an impermeable, adult state $(22,23)$. One reason for maturation as a response to diet transition may be to prevent influx of higher concentrations of unbound FFAs and pancreatic digestive enzymes such as pancreatic lipase, necessary for digestion of nutrients other than milk, into the intestinal wall.

Given that digested full-term formula is as cytotoxic as the preterm formula, it is also possible that full-term infants with a genetic predisposition to a permeable gut could be affected by this mechanism. For example, although their intestinal permeability as infants has not yet been studied, children with autism spectrum disorders have been reported to be more likely to have leaky guts $(24,25)$ and gastrointestinal problems (26). One study reported that infants fed exclusively on breast milk for longer periods are less likely to develop autism spectrum disorders as compared with those weaned to formula earlier (27). Given that survivors of NEC have documented neurodevelopmental problems later in life (28), it is conceivable that the mechanism presented here may also play a role in autism spectrum disorders.

Although we employed a broad range of enzyme concentrations, one limitation of this study is that we used either isolated pancreatic lipase or the lipases from an adult rat for both the milk and formula digestions. We did not include predigestion by gastric and lingual lipases, which cleave only a small fraction of available ester bonds but may prime milk fats for further digestion in the intestine (29), nor did we include pancreatic lipase-related protein 2 or exogenous bile salt-sensitive lipase. However, as mentioned above, pancreatic lipase-related protein 2 may be even less efficient at lipid digestion in milk than pancreatic lipase (16), so neonates receiving fresh breast milk may be exposed to even lower FFA levels and be more protected from cytotoxicity than revealed by our study.

Our findings suggest a number of possible strategies to decrease the rate of FFA generation and limit cytotoxicity from formula for infants at risk for NEC or inherited conditions associated with permeable intestines. Formula may be further optimized by examining the risks vs. benefits of decreasing the fat content or reducing the rate of lipolysis with pancreatic lipase through choice of fats or fat globule diameters, or by covering fat globules with a membrane similar to that around breast milk fat globules. Other possible methods to reduce cytotoxicity include the addition of fatty acid binding proteins and/or lipase inhibitors.

Overall, our results reveal a major ability of breast milk to reduce cytotoxicity that is not matched by formula, which may guide feeding practices of premature infants and infants with abnormal or increased intestinal permeability. It remains to be investigated via intestinal aspirates whether the actual intestinal luminal content of formula or breast milk-fed infants is cytotoxic, whether there are significant differences in their free fatty acid profiles in vivo, and whether intervention to reduce unbound FFAs in the intestinal lumen can prevent intestinal damage and/or death in NEC in animal models.

\section{METHODS}

\section{Human Milk Collection and Handling of Milk and Formula}

The Institutional Review Board and the Animal Subjects Committee of the University of California, San Diego, reviewed and approved all human and animal protocols, respectively. Human milk was obtained with informed consent from healthy volunteer mothers $(N=12)$ via breast pump. A full expression was collected to mix fore- and hindmilk. Because breast milk stored at temperatures of $-20^{\circ} \mathrm{C}$ or greater can become cytotoxic due to the formation of FFAs by milk lipases (30), we used fresh breast milk collected in the morning rather than a mixture of breast milks collected over $24 \mathrm{~h}$. The milk was kept at $4^{\circ} \mathrm{C}$ from the time of expression until it could be aliquoted (within $2 \mathrm{~h}$ of expression) for immediate use or storage $\left(-80^{\circ} \mathrm{C}\right)$.

Unless otherwise noted, we used the full-term infant formula Enfamil Infant reconstituted with water from a concentrated liquid form. Some cytotoxicity measurements were repeated using two additional powdered full-term formulas (Similac Advance and Similac Soy, Abbott Laboratories, Abbott Park, IL), four preterm infant formulas used in hospitals (Enfamil Premature 20 and $24 \mathrm{kcal} / \mathrm{oz}$ formulas and Similac Special Care 20 and $24 \mathrm{kcal} / \mathrm{oz}$ formulas), and two preterm post-discharge infant formulas (Enfamil EnfaCare $22 \mathrm{kcal} / \mathrm{oz}$ and Similac Expert Care NeoSure $22 \mathrm{kcal} / \mathrm{oz}$ ).

\section{Cytotoxicity Studies}

We assayed for cytotoxicity using three cell types found in the intestine obtained from three different species: human neutrophils, primary bovine aortic endothelial cells (a gift from Shu Chien, University of California, San Diego), and primary rat small IECs (from ATCC, Manassas, VA). Neutrophils, isolated as previously described (5) from blood drawn from healthy donors, were logistically convenient for analysis of fresh breast milk and were used for most experiments, although some fresh milk $(n=3)$ was also assayed using endothelial cells. The stored milk of all 12 mothers was tested on the same day on the epithelial cells (storage times at $-80^{\circ} \mathrm{C}$ varied from 26 to $236 \mathrm{~d}$ (mean \pm SD: $110 \pm 62 \mathrm{~d}$ )).

Sample preparation. We digested human milk or formula with PBS (as control), porcine pancreatic lipase (Sigma-Aldrich, St Louis, MO), bovine trypsin and chymotrypsin (proteases) (Sigma-Aldrich), all three enzymes in combination (lipase + proteases), or luminal fluid from the rat small intestine obtained after euthanasia $(120 \mathrm{mg} / \mathrm{kg}$ sodium pentobarbital) of a male Wistar rat. The exterior of the rat small intestine was rinsed in saline and its contents flushed out with $40 \mathrm{ml}$ of saline. The luminal effluent (in $40 \mathrm{ml}$ saline) was immediately homogenized, centrifuged $\left(16000 \mathrm{~g}, 20 \mathrm{~min}, 4^{\circ} \mathrm{C}\right)$, and the supernatant aliquoted and stored $\left(-80^{\circ} \mathrm{C}\right)$ until use. At this dilution, luminal fluid is not cytotoxic on its own, but it can generate cytotoxicity if food is present as substrate for its enzymes (5).

Formula or human milk was incubated for $2 \mathrm{~h}\left(37^{\circ} \mathrm{C}\right)$ (similar to the transit time through an infant small intestine) after mixing 4:1 (vol:vol) with buffer or enzymes (1:1 in the case of luminal fluid). Final concentration of enzymes was $1 \mathrm{mg} / \mathrm{ml}$ for studies on neutrophils and $0.1 \mathrm{mg} /$ $\mathrm{ml}$ for studies on endothelial and epithelial cells. These concentrations bracket and are on the order of concentrations in the intestinal lumen of human infants (31). Enzymes in buffer alone, or enzymes plus milk or formula but no digestion time, were the controls for neutrophil and cell-culture studies, respectively. Because fat particulates interfere with quantification by flow cytometry, after digestion milk and formula samples for neutrophil cytotoxicity studies were centrifuged $(16000 \mathrm{~g}$, $20 \mathrm{~min}, 4^{\circ} \mathrm{C}$ ) to obtain the supernatant under the solid fat layer. These skimmed samples were then incubated with neutrophils. No skimming was required for cytotoxicity experiments on endothelial or epithelial cell cultures as samples could be aspirated without disturbing cells. 
Neutrophil cytotoxicity assay. Neutrophils were incubated 1:1 with sample $\left(10^{6}\right.$ cells $/ \mathrm{ml}$ final, $1 \mathrm{~h}$, room temperature) before adding the fluorescent life/death indicator PI ( $1 \mu \mathrm{mol} / \mathrm{l}$ final; Sigma-Aldrich) and taking an immediate reading in a flow cytometer. PI-positive and PI-negative cells were gated from dot plots as previously described (5), excluding particulates from the milk or formula samples, and cell death reported as the percentage of total cells that were PI positive. A sample was deemed "cytotoxic" if it caused more than $15 \%$ cell death measured in this fashion.

Endothelial and epithelial cell cytotoxicity assays. Bovine aortic endothelial cells or IECs were grown in 96-well cell culture-treated plates and allowed to reach confluency overnight. Immediately after growth media aspiration, cells cultures were incubated with $80 \mu \mathrm{l}$ of sample per well in triplicate for $5 \mathrm{~min}$ at room temperature. Following treatment, cells were washed twice with complete growth media and then incubated with $10 \mu \mathrm{g} / \mathrm{ml}$ PI for $2 \mathrm{~min}$. Treatment with $0.1 \%$ Triton X-100 (Fisher Scientific, Pittsburgh, PA) in PBS for $30 \mathrm{~s}$ immediately before the addition of PI served as a positive control for total (100\%) cell death. Negative controls were untreated and stained for PI. After PI treatment, PI was rinsed and cultures were kept in their respective complete media for immediate live cell imaging.

Brightfield and fluorescent images were acquired in three fields per well and the number of PI positive (i.e., dead) cells averaged over each well for formula or over each donor for milk. Completely confluent cell areas were used to quantify cell death. Cell death was normalized to a percentage by the average number of PI-positive cells detected after treatment with Triton X-100. A given sample was deemed "cytotoxic" if it caused more than $5 \%$ cell death measured in this fashion.

\section{Fatty Acid Interventions and Quantification}

FFAs in the body are usually found bound to proteins such as albumin and specific fatty acid binding proteins. In this study, we refer to total FFA concentration as the sum of bound and unbound FFA concentrations.

Total FFA concentration was determined in a 96-well plate using the Free Fatty Acids Half-Micro Test kit (Roche Applied Sciences, Indianapolis, IN). All samples were prediluted 10-fold to bring concentrations within the linear range of the assay $(<1 \mathrm{mmol} / \mathrm{l})$, with reported values corrected to the original concentrations. We determined bound FFA concentrations by repeating the measure after filtration through three to five glass fiber prefilters (Pall-Gellman, Port Washington, NY), which remove unbound, but not bound FFAs (Figure 3). All samples contained $<0.5 \mathrm{mmol} / \mathrm{l} \mathrm{FFA}$ after dilution and were therefore within the capacity of five filters to remove all unbound FFAs (Figure 3).

To determine the role of FFAs in formula cytotoxicity, formula samples were treated with orlistat $(0.25 \mathrm{mg} / \mathrm{ml}$ final; Sigma-Aldrich) to inhibit lipase activity, treated with fatty acid-free bovine serum albumin $(20 \mathrm{mg} / \mathrm{ml}$ final; Sigma-Aldrich) to bind FFAs, or filtered through glass fiber filters to remove unbound FFAs.

\section{Statistics}

Data are presented as means \pm SD. Statistical analysis was performed in Excel and SPSS. Single or multifactor ANOVA or mixed ANOVA was completed for experiments with multiple groups followed by Bonferroni correction for pair-wise $t$-test comparisons.

\section{ACKNOWLEDGMENTS}

We are grateful to the mothers who graciously donated their milk for use in this study and to Emily Blumenthal for her statistical assistance.

\section{STATEMENT OF FINANCIAL SUPPORT}

Supported by National Institutes of Health grants NS071580 and GM85072.

Disclosure: The authors declared no conflict of interest.

\section{REFERENCES}

1. Anand RJ, Leaphart CL, Mollen KP, Hackam DJ. The role of the intestinal barrier in the pathogenesis of necrotizing enterocolitis. Shock 2007;27:124-33.

2. Lin PW, Stoll BJ. Necrotising enterocolitis. Lancet 2006;368:1271-83.
3. Lucas A, Cole TJ. Breast milk and neonatal necrotising enterocolitis. Lancet 1990;336:1519-23.

4. Meinzen-Derr J, Poindexter B, Wrage L, Morrow AL, Stoll B, Donovan EF. Role of human milk in extremely low birth weight infants' risk of necrotizing enterocolitis or death. J Perinatol 2009;29:57-62.

5. Penn AH, Hugli TE, Schmid-Schönbein GW. Pancreatic enzymes generate cytotoxic mediators in the intestine. Shock 2007;27:296-304.

6. Penn AH, Schmid-Schönbein GW. The intestine as source of cytotoxic mediators in shock: free fatty acids and degradation of lipid-binding proteins. Am J Physiol Heart Circ Physiol 2008;294:H1779-92.

7. Isaacs CE, Kashyap S, Heird WC, Thormar H. Antiviral and antibacterial lipids in human milk and infant formula feeds. Arch Dis Child 1990;65:861-4.

8. Sun Z, Wang X, Deng X, et al. The influence of intestinal ischemia and reperfusion on bidirectional intestinal barrier permeability, cellular membrane integrity, proteinase inhibitors, and cell death in rats. Shock 1998;10:203-12.

9. Wang B, Huang Q, Zhang W, Li N, Li J. Lactobacillus plantarum prevents bacterial translocation in rats following ischemia and reperfusion injury. Dig Dis Sci 2011;56:3187-94.

10. Rosário HS, Waldo SW, Becker SA, Schmid-Schönbein GW. Pancreatic trypsin increases matrix metalloproteinase- 9 accumulation and activation during acute intestinal ischemia-reperfusion in the rat. Am J Pathol 2004;164:1707-16.

11. Weaver LT, Laker MF, Nelson R. Intestinal permeability in the newborn. Arch Dis Child 1984;59:236-41.

12. Taylor SN, Basile LA, Ebeling M, Wagner CL. Intestinal permeability in preterm infants by feeding type: mother's milk versus formula. Breastfeed Med 2009;4:11-5.

13. Peng L, He Z, Chen W, Holzman IR, Lin J. Effects of butyrate on intestinal barrier function in a Caco-2 cell monolayer model of intestinal barrier. Pediatr Res 2007;61:37-41.

14. Waligora-Dupriet AJ, Dugay A, Auzeil N, et al. Short-chain fatty acids and polyamines in the pathogenesis of necrotizing enterocolitis: Kinetics aspects in gnotobiotic quails. Anaerobe 2009;15:138-44.

15. Michalski MC, Briard V, Michel F, Tasson F, Poulain P. Size distribution of fat globules in human colostrum, breast milk, and infant formula. J Dairy Sci 2005;88:1927-40.

16. Berton A, Sebban-Kreuzer C, Rouvellac S, Lopez C, Crenon I. Individual and combined action of pancreatic lipase and pancreatic lipase-related proteins 1 and 2 on native versus homogenized milk fat globules. Mol Nutr Food Res 2009;53:1592-602.

17. Lien EL, Boyle FG, Yuhas R, Tomarelli RM, Quinlan P. The effect of triglyceride positional distribution on fatty acid absorption in rats. J Pediatr Gastroenterol Nutr 1997;25:167-74.

18. Catassi C, Bonucci A, Coppa GV, Carlucci A, Giorgi PL. Intestinal permeability changes during the first month: effect of natural versus artificial feeding. J Pediatr Gastroenterol Nutr 1995;21:383-6.

19. Werner H, Amarant T, Millar RP, Fridkin M, Koch Y. Immunoreactive and biologically active somatostatin in human and sheep milk. Eur J Biochem 1985;148:353-7.

20. Gyr K, Beglinger C, Köhler E, Trautzl U, Keller U, Bloom SR. Circulating somatostatin. Physiological regulator of pancreatic function? J Clin Invest 1987;79:1595-600.

21. Yang Y, Sanchez D, Figarella C, Lowe ME. Discoordinate expression of pancreatic lipase and two related proteins in the human fetal pancreas. Pediatr Res 2000;47:184-8.

22. Boudry G, Péron V, Le Huërou-Luron I, Lallès JP, Sève B. Weaning induces both transient and long-lasting modifications of absorptive, secretory, and barrier properties of piglet intestine. J Nutr 2004;134: 2256-62.

23. Dvorak B, McWilliam DL, Williams CS, et al. Artificial formula induces precocious maturation of the small intestine of artificially reared suckling rats. J Pediatr Gastroenterol Nutr 2000;31:162-9.

24. D’Eufemia P, Celli M, Finocchiaro R, et al. Abnormal intestinal permeability in children with autism. Acta Paediatr 1996;85:1076-9. 
25. de Magistris L, Familiari V, Pascotto A, et al. Alterations of the intestinal barrier in patients with autism spectrum disorders and in their first-degree relatives. J Pediatr Gastroenterol Nutr 2010;51:418-24.

26. Smith RA, Farnworth H, Wright B, Allgar V. Are there more bowel symptoms in children with autism compared to normal children and children with other developmental and neurological disorders?: A case control study. Autism 2009;13:343-55.

27. Schultz ST, Klonoff-Cohen HS, Wingard DL, et al. Breastfeeding, infant formula supplementation, and Autistic Disorder: the results of a parent survey. Int Breastfeed J 2006;1:16.
28. Neubauer AP, Voss W, Kattner E. Outcome of extremely low birth weight survivors at school age: the influence of perinatal parameters on neurodevelopment. Eur J Pediatr 2008;167:87-95.

29. Roman C, Carriere F, Villeneuve P, et al. Quantitative and qualitative study of gastric lipolysis in premature infants: do MCT-enriched infant formulas improve fat digestion? Pediatr Res 2007;61:83-8.

30. Sakaguchi M, Tomomasa T, Kuroume T. Cytolytic action of stored human milk on blood cells in vitro. J Perinat Med 1995;23:293-300.

31. Norman A, Strandvik B, Ojamäe O. Bile acids and pancreatic enzymes during absorption in the newborn. Acta Paediatr Scand 1972;61:571-6. 